ORNL/LTR-2021/1903

\title{
Additively Manufactured Power Poles
}

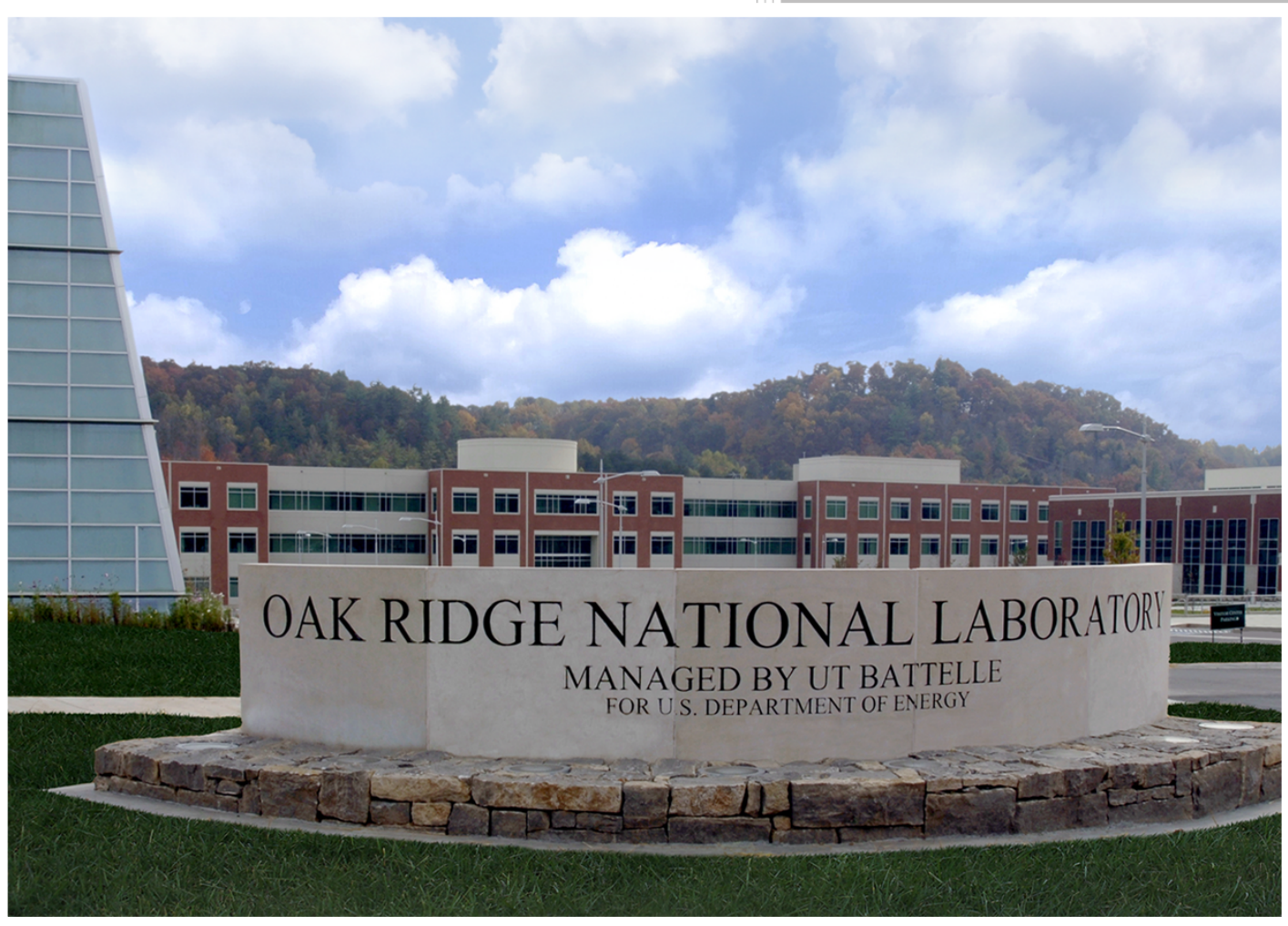

Brian Post

Halil Tekinalp

Peter Wang

Celest Atkins

Alex Roschli

February 2020

Approved for Public Release. Distribution is Unlimited. 


\section{DOCUMENT AVAILABILITY}

Reports produced after January 1, 1996, are generally available free via US Department of Energy (DOE) SciTech Connect.

Website http://www.osti.gov/scitech/

Reports produced before January 1, 1996, may be purchased by members of the public from the following source:

National Technical Information Service

5285 Port Royal Road

Springfield, VA 22161

Telephone 703-605-6000 (1-800-553-6847)

TDD 703-487-4639

Fax 703-605-6900

E-mail info@ntis.gov

Website http://www.ntis.gov/help/ordermethods.aspx

Reports are available to DOE employees, DOE contractors, Energy Technology Data Exchange representatives, and International Nuclear Information System representatives from the following source:

Office of Scientific and Technical Information

PO Box 62

Oak Ridge, TN 37831

Telephone 865-576-8401

Fax 865-576-5728

E-mail reports@osti.gov

Website http://www.osti.gov/contact.html

This report was prepared as an account of work sponsored by an agency of the United States Government. Neither the United States Government nor any agency thereof, nor any of their employees, makes any warranty, express or implied, or assumes any legal liability or responsibility for the accuracy, completeness, or usefulness of any information, apparatus, product, or process disclosed, or represents that its use would not infringe privately owned rights. Reference herein to any specific commercial product, process, or service by trade name, trademark, manufacturer, or otherwise, does not necessarily constitute or imply its endorsement, recommendation, or favoring by the United States Government or any agency thereof. The views and opinions of authors expressed herein do not necessarily state or reflect those of the United States Government or any agency thereof. 
Energy and Transportation Science Division

Oak Ridge National Laboratory

\title{
Additively Manufactured Power Poles
}

\author{
Authors \\ Brian Post \\ Halil Tekinalp \\ Alex Roschli \\ Peter Wang \\ Celeste Atkins
}

Date Published:

February, 2020

\author{
Prepared by \\ OAK RIDGE NATIONAL LABORATORY \\ Oak Ridge, Tennessee 37831-6283 \\ managed by \\ UT-BATTELLE, LLC \\ for the \\ US DEPARTMENT OF ENERGY \\ under contract DE-AC05-00OR22725
}

Approved For Public Release 



\section{CONTENTS}

Page

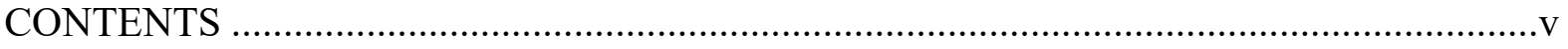

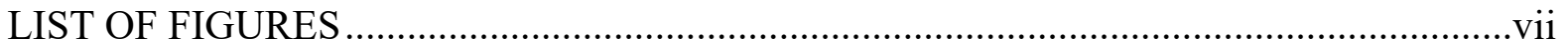

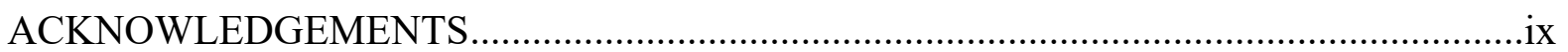

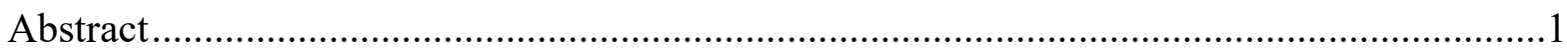

1. Additively Manufactured Power Poles ....................................................................

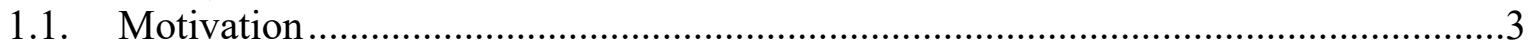

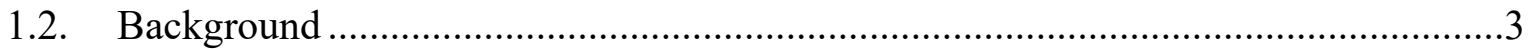

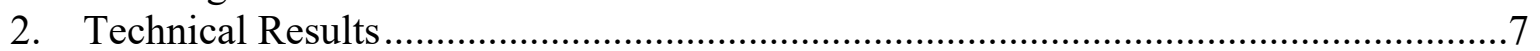

2.1. Material Selection...................................................................................... 7

2.2. Glass Fiber (GF) Cellulose Ester (CE) .....................................................

2.3. Glass Fiber (GF) Recycled Polycarbonate (rPC) .........................................

2.4. Bamboo Fiber-Glass Fiber Polystyrene ............................................................ 10

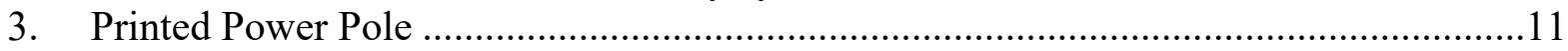

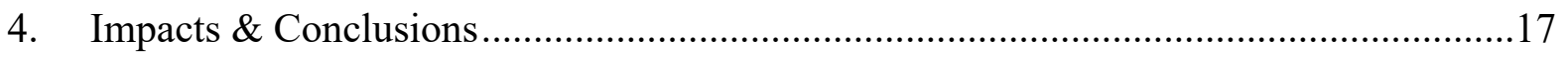




\section{LIST OF FIGURES}

Figure 1: Printed Bamboo Pavilion ................................................................................ 3

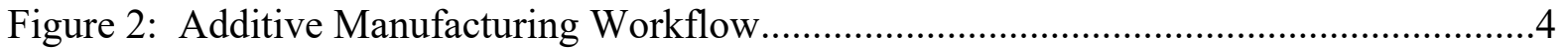

Figure 3: Polymer extrusion ....................................................................................... 4

Figure 4: Big Area Additive Manufacturing ...........................................................

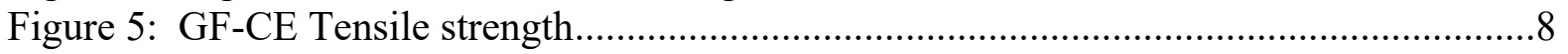

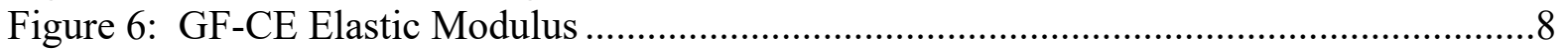

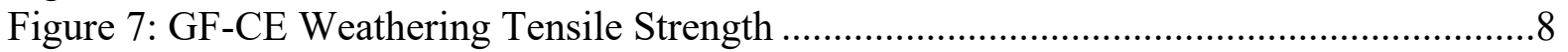

Figure 8: GF-CE Weathering Modulus ...................................................................

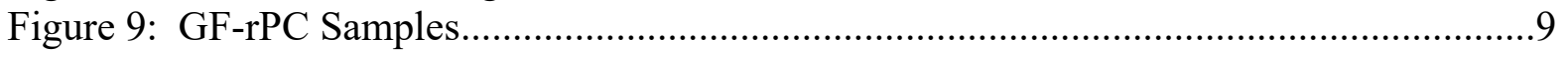

Figure 10: GF-rPC Tensile Strength ........................................................................

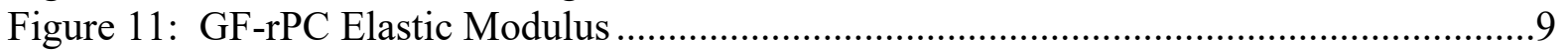

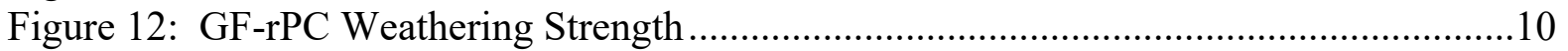

Figure 13: GF-rPC Weathering Modulus ........................................................................ 10

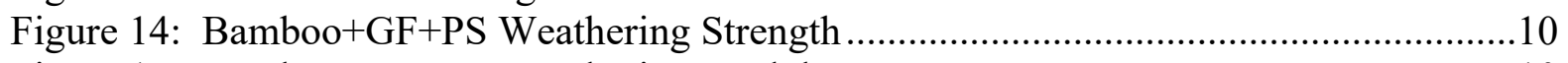

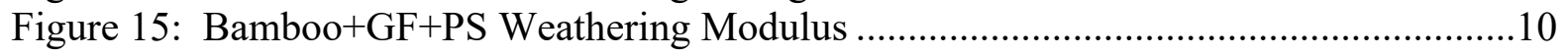

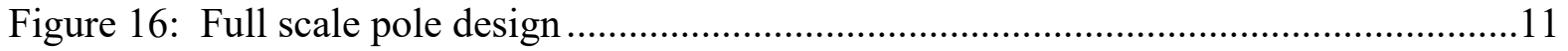

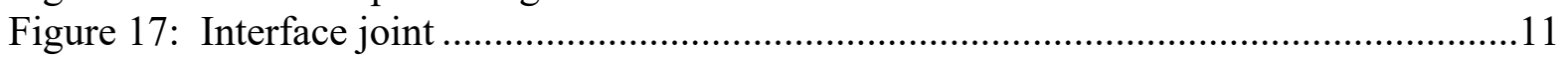

Figure 18: Prototype pole section .............................................................................. 12

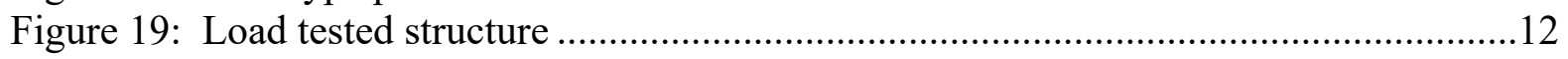

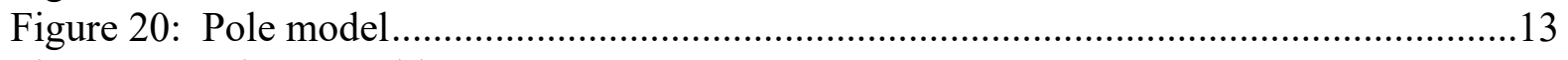

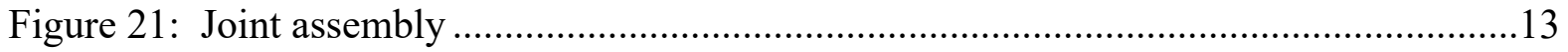

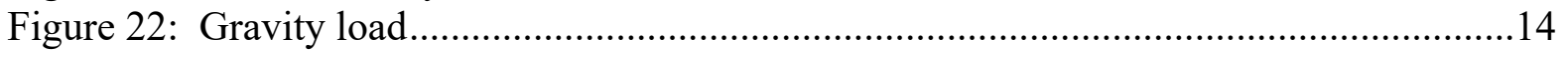

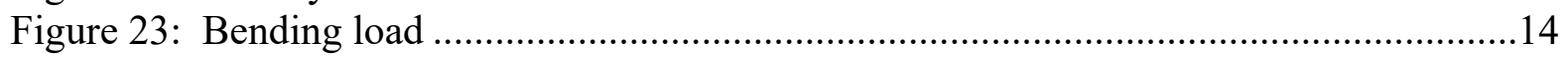

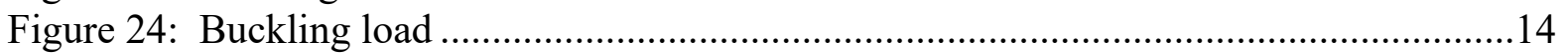

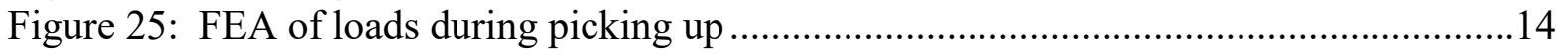

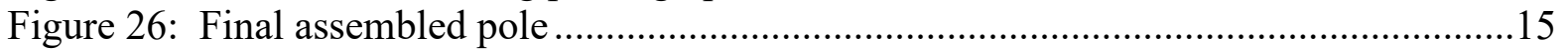

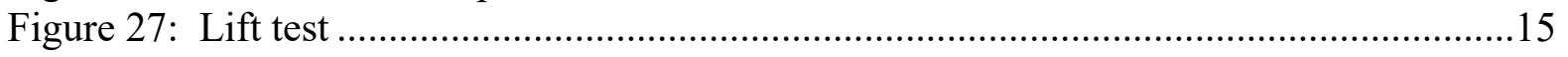

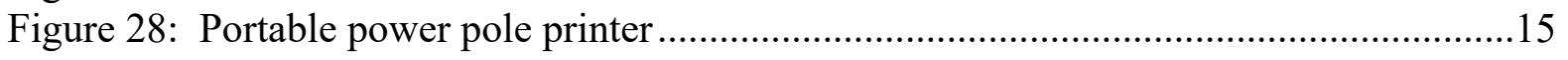

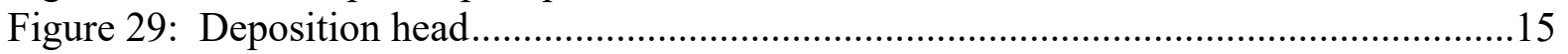




\section{ACKNOWLEDGEMENTS}

This effort was conducted as an Office of Electricity project within the Oak Ridge National Laboratory (ORNL) Manufacturing Demonstration Facility (MDF) sponsored by the US Department of Energy Advanced Manufacturing Office (CPS Agreement Number 24761). The goal of the effort was to engage industry partners to participate in short-term, collaborative projects within the Manufacturing Demonstration Facility (MDF) to assess applicability and of new energy efficient manufacturing technologies. Research was sponsored by the U.S. Department of Energy, Office of Energy Efficiency and Renewable Energy, Office of Electricity, under contract DE-AC05-

00OR22725 with UT-Battelle, LLC. The team would likewise like to acknowledge Techmer PM and Eastman Chemical for assistance in synthesizing and production new composite biomaterials in support of the project. 


\begin{abstract}
The objective of this project was to explore the utility of native grown biomaterials for the portable production of power poles. In this Phase 1 project, activities were broken into two tasks: 1) baseline efforts to show feasibility of printed biomaterial power poles and 2) produce a conceptual design of portable pole production. The results were very promising, showing sufficient mechanical properties from printed biomaterials as well as conceptual designs for, and successful demonstration of, printed power poles.
\end{abstract}




\section{ADDITIVELY MANUFACTURED POWER POLES}

\subsection{MOTIVATION}

Oak Ridge National Laboratory's Manufacturing Demonstration Facility has pioneered the area of large-scale composite additive manufacturing (AM). Conventional AM processes are limited to small parts (less than one cubic foot) and slow deposition rates (less than 5 cubic inches per hour) using expensive feedstocks (in excess of $\$ 50 / \mathrm{lb}$ ). Big Area Additive Manufacturing (BAAM) is a scalable (in excess of 1000 cubic feet parts), high speed (scalable beyond $1000 \mathrm{ci} / \mathrm{hr}$ ), low cost process (less than $\$ 5 / \mathrm{lb}$ ). The BAAM technology has been shown to enable low cost, rapid manufacture of tooling and end-use parts. Recent efforts have focused on exploring biologically based feedstocks. Specifically, the team has recently developed and demonstrated the ability to rapidly manufacture bamboo-reinforced bio-thermoplastics.

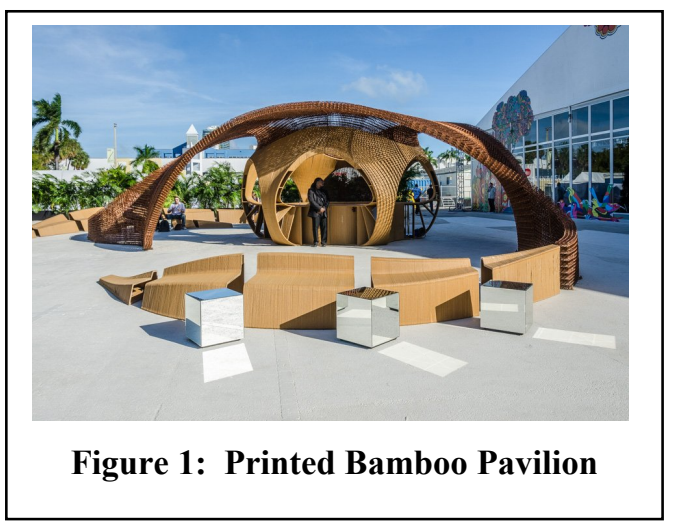
Additional efforts have focused on expanding the BAAM technology to enable multiple materials on a single part. This project leveraged these efforts by exploring the feasibility of using BAAM to produce power poles from multiple biologically based feedstocks. The goal of this project was to explore the potential of creating more resilient power poles through an integration multimaterial design that discretely blends the bamboo material with an elastic material in discrete locations and with novel geometries.

Efforts were divided into two tasks. The goal of the first task was to quantify the cost, performance (strength, stiffness) and production rate of power poles produced from multiple biomaterials using BAAM. The second task of the project was to develop a conceptual model for portable pole production. The vision was a system that can be transported on a 53-foot tractor trailer bed. Raw materials would either be transported with a truck or, preferably, raw material would be locally sourced and processed on the same system (e.g. local biomaterials, trees, etc.).

\subsection{BACKGROUND}

Additive Manufacturing is based on building three-dimensional structures bit by bit, layer by layer. The basic approach for all additive processes is shown in Figure 2. The object starts with a computer aided design (CAD) model. Each printing process has, as an input, a slicing program that decomposes the part into horizontal layers (e.g. slices). Each layer is a virtual cross section of the part. The slicing algorithm then decomposes each layer into a path for the deposition system to follow to fill the layer with material. Every additive process follows this general work flow. There are currently seven different additive processes enabling production of polymers, composites, ceramics and metals. The approach used for this investigation is polymer extrusion (see Figure 3). 


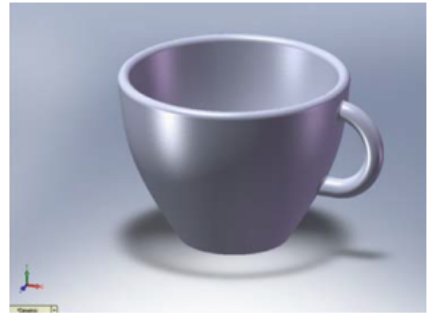

CAD Solid Model

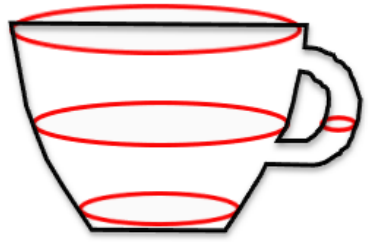

Layer-specific tool paths

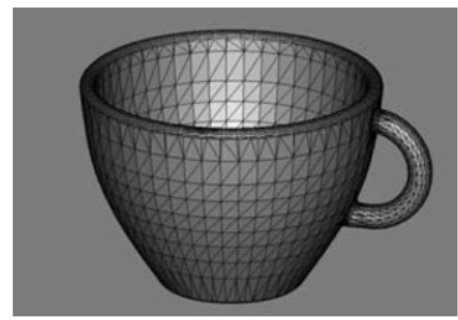

Faceted Model

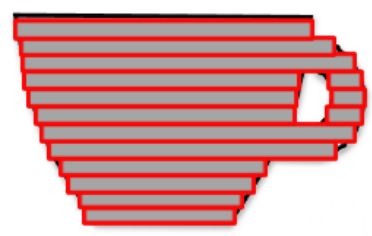

Build each layer on top of previous ones

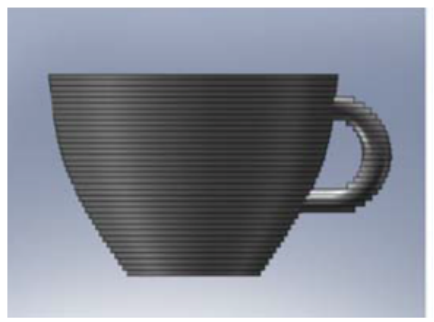

Virtually slice

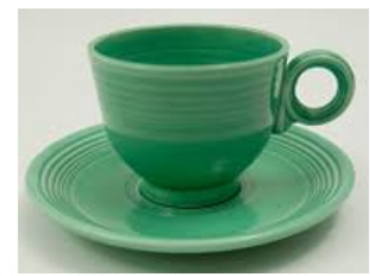

Finished Part

Figure 2: Additive Manufacturing Workflow

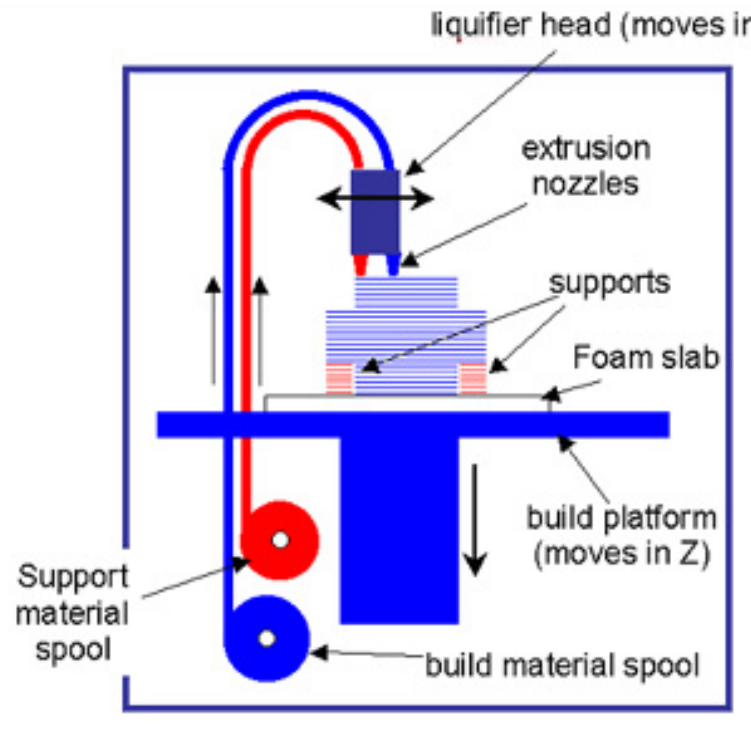

Figure 3: Polymer extrusion

The conventional polymer extrusion process uses a plastic wire as the feed material into the process. These systems are typically very small and slow. ORNL has pioneered large scale polymer extrusion, called Big Area Additive Manufacturing (BAAM), using injection molding pellets as the feedstock (see Figure 4). 


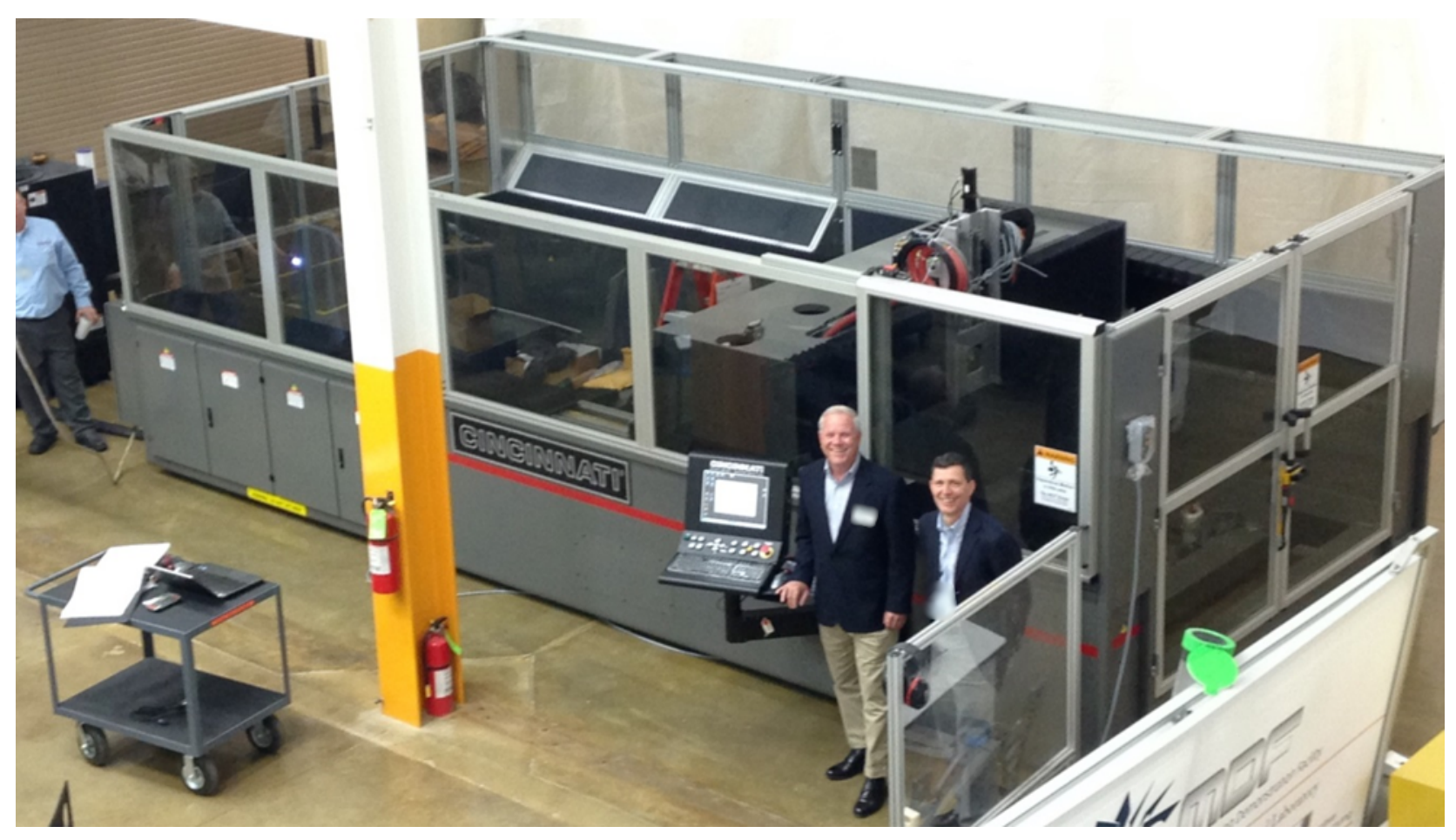

Figure 4: Big Area Additive Manufacturing

By transforming from wire to pellets, it is possible to load the polymer materials with different reinforcements such as glass fiber, carbon fiber and biofibers such as bamboo. In terms of material properties, as the material is extruded, the flow fields cause the fibers to align to the bead. Therefore, all the benefits of the fiber reinforcement are contained in the layer (X-Y direction) with a slight degradation in properties in the vertical direction (Z). 


\section{TECHNICAL RESULTS}

The first task, executed over a 9-month period, focused on showing the feasibility of printing power poles. ORNL worked with ConEdison on the design and requirements for the pole.

\subsection{Material Selection}

Three different materials were evaluated for feasibility for printed power poles:

- Glass fiber- cellulose ester (Eastman Chemical); Cellulose acetate propionate (CAP)

- Glass fiber reinforced recycled polycarbonate

- Bamboo fiber-glass fiber reinforced polystyrene

Materials were identified, compounded into small lot samples, and then scaled to pellet feedstock for printing evaluation. Weathering tests were carried out on printed samples for 1000 hours following SAE J2412 protocol. The applied weathering cycle is a 1 to 10 ratio; thus, the testing protocol corresponded to 10,000 hours (approximately 420 days) of exposure. The SAE J2412 conditions were:

- Inner lamp filter: quartz

- Outer lamp filter: Borosilicate

- Lamp irradiance level: 0.55 watts X meter-2 X nm-1

- Chamber air temperature - light cycle: $62^{\circ} \mathrm{C}$

- Chamber air temperature - dark cycle: $38^{\circ} \mathrm{C}$

- Chamber relative humidity - light cycle: $50 \%$

- Chamber relative humidity - dark cycle: $95 \%$

- Black panel temperature - light cycle: $89^{\circ} \mathrm{C}$

- Black panel temperature - dark cycle: $38^{\circ} \mathrm{C}$

The timing of light/dark cycle with sample surface spray is shown in Table 1.

Table 1. Timing of light/dark cycle with sample surface spray

\begin{tabular}{|c|c|c|c|}
\hline Segment & Light (min.) & Dark (min.) & Spray \\
\hline 1 & None & 60 & None \\
\hline 2 & 228 & N.A. & None \\
\hline
\end{tabular}

\subsection{Glass Fiber (GF) Cellulose Ester (CE)}

The first material under evaluation was glass fiber (GF) cellulose ester (CE) from Eastman Chemical. Approximately 1500 lbs of 20\% GF-CE pellets were prepared by Eastman Chemical. Tensile data both in $\mathrm{x}$ - and $\mathrm{z}$ - directions with up to $10 \%$ GF-CE BAAM-printed samples are given below. 


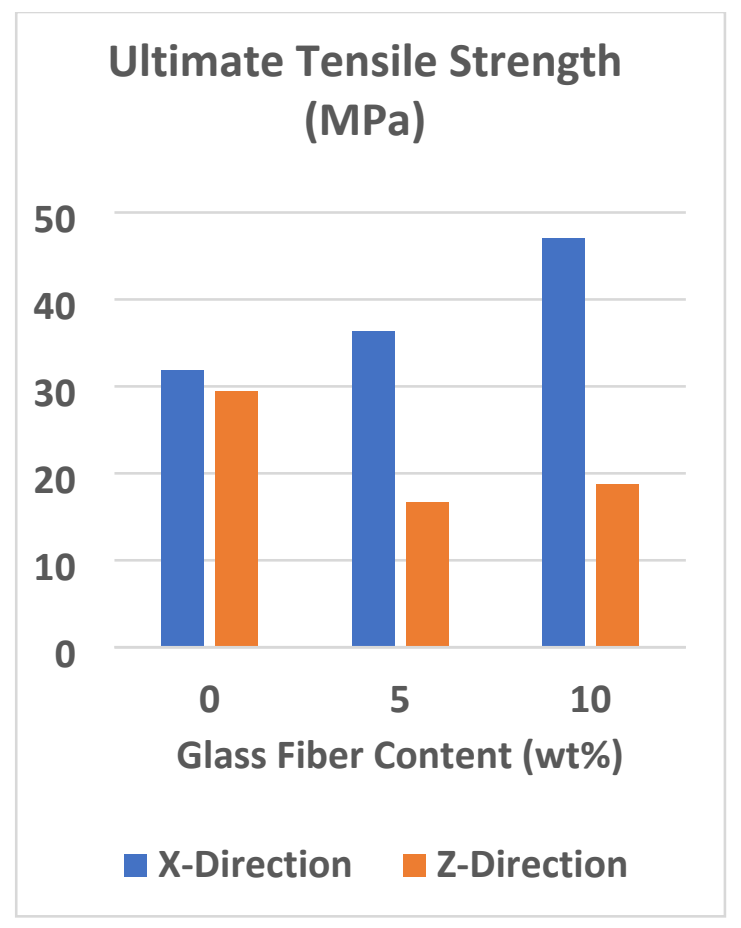

Figure 5: GF-CE Tensile strength

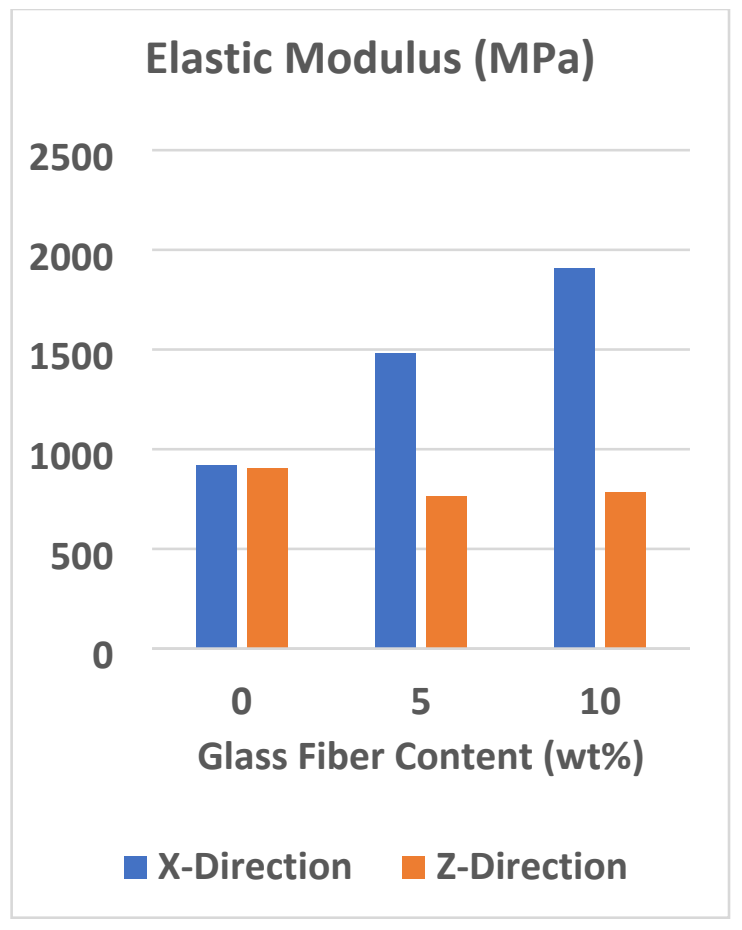

Figure 6: GF-CE Elastic Modulus

Hexagons were printed with the $20 \%$ GF-CE feedstock. Tensile specimens were prepared and weatherized. The tensile testing results in the $\mathrm{x}$ and $\mathrm{z}$ directions both before and after weathering tests are given below. The material was printed in BAAM-A and some feeding problems were experienced during the run causing insufficiently filled layers. This must be taken into account while evaluating $\mathrm{z}$-direction properties. The process was repeated in BAAM-B, and the feeding issue seen in BAAM-A was not experienced.

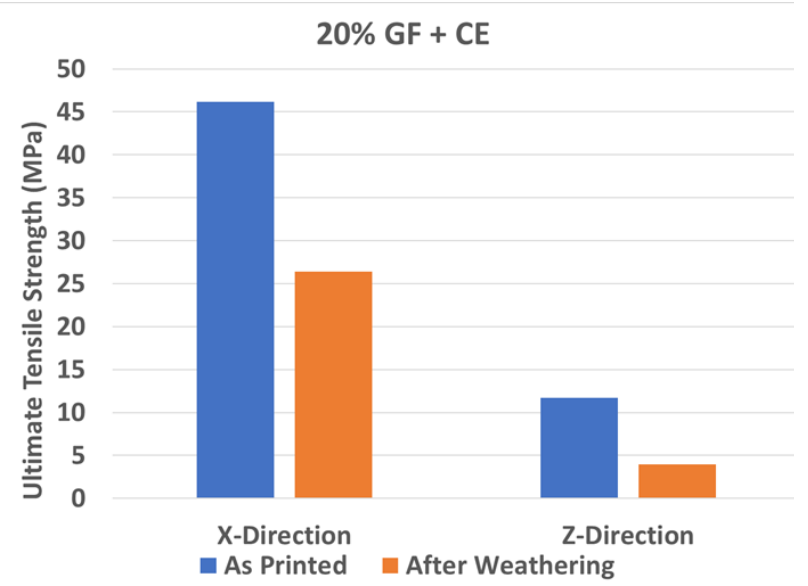

Figure 7: GF-CE Weathering Tensile Strength

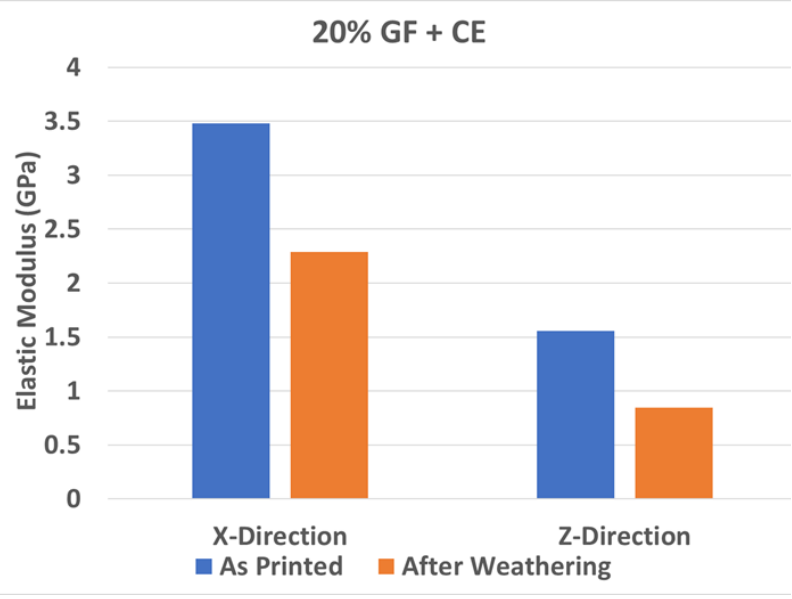

Figure 8: GF-CE Weathering Modulus

\subsection{Glass Fiber (GF) Recycled Polycarbonate (rPC)}

Approximately $900 \mathrm{lbs}$ of 30\% GF rPC pellets were prepared by Techmer PM. Walls and hexagons were manufactured for process parameter development and tensile testing. Tensile specimens were cut in both 
the X-and Z-directions on the BAAM-printed samples.

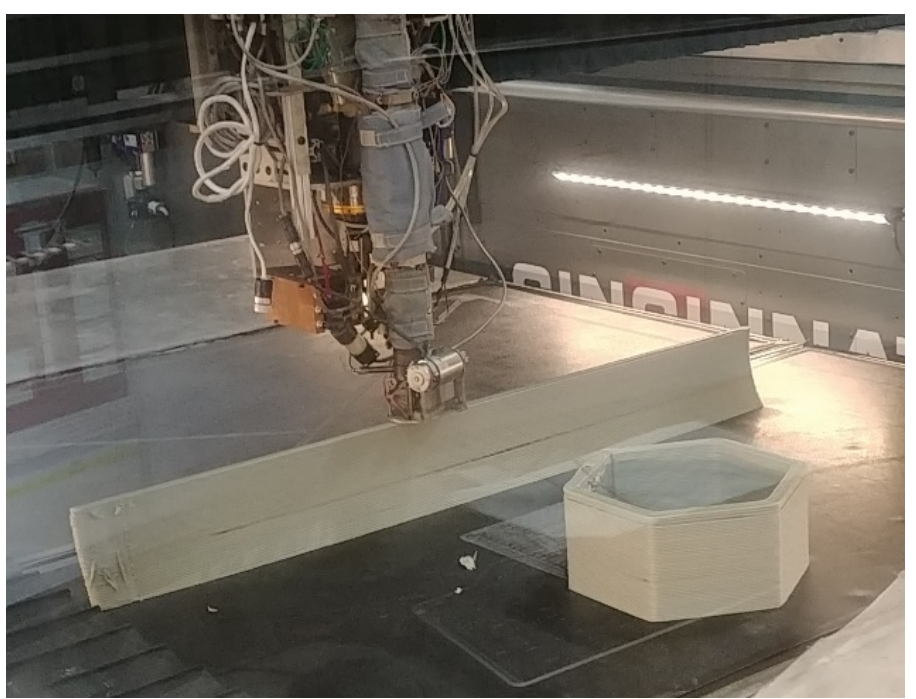

Figure 9: GF-rPC Samples

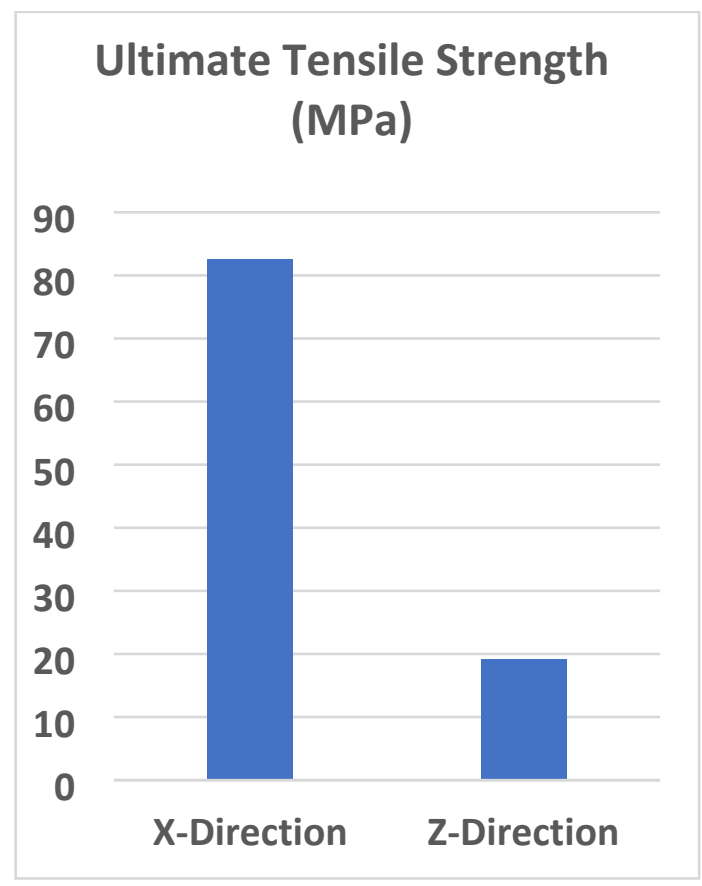

Figure 10: GF-rPC Tensile Strength

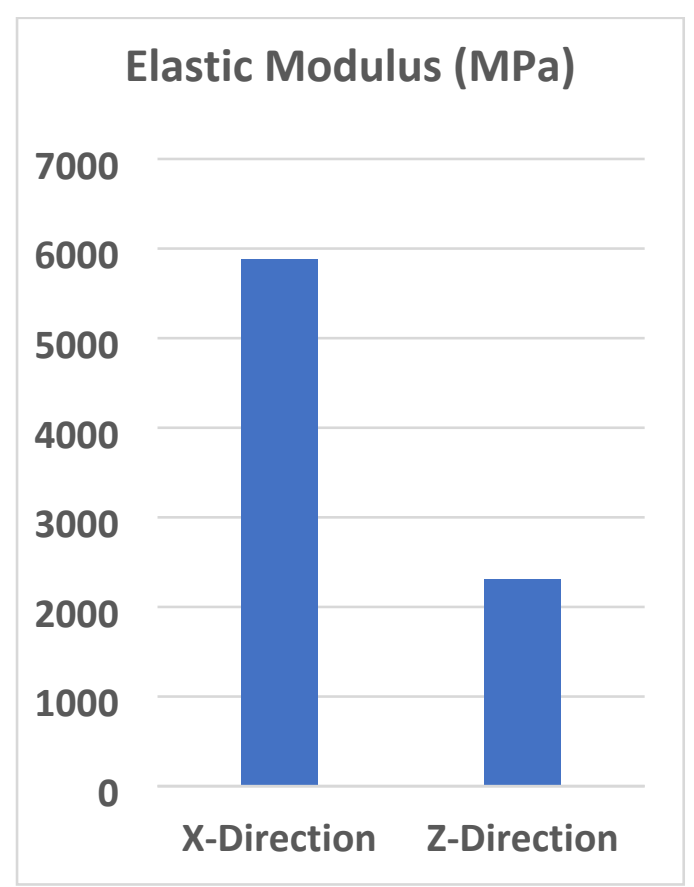

Figure 11: GF-rPC Elastic Modulus

Tensile specimens were also weathered for $1000 \mathrm{hrs}$ and tensile properties in both the $\mathrm{x}$ and $\mathrm{z}$ directions were compared before and after weathering tests, as shown below. 


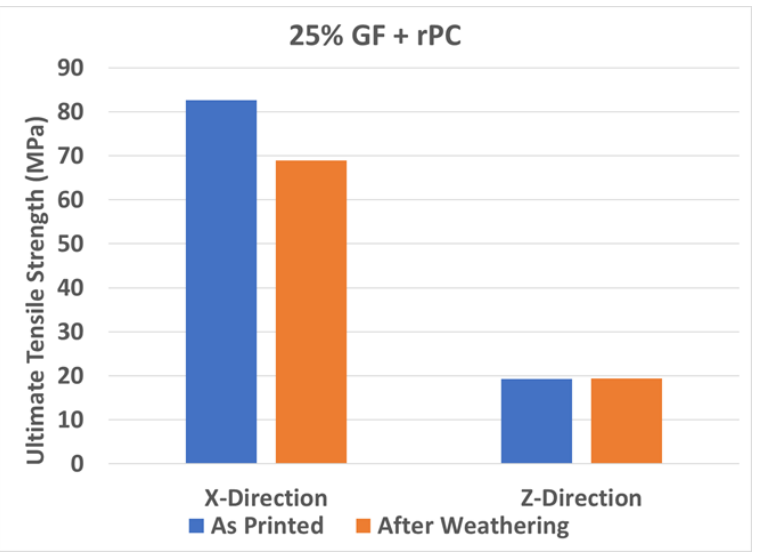

Figure 12: GF-rPC Weathering Strength

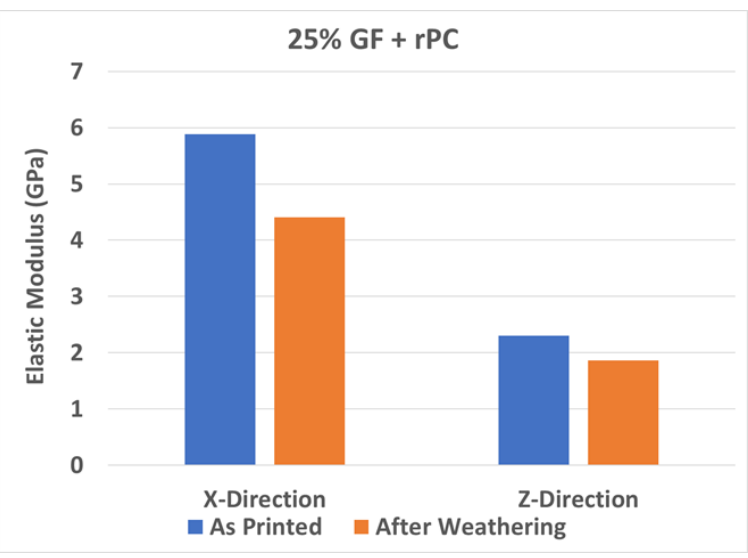

Figure 13: GF-rPC Weathering Modulus

\subsection{Bamboo Fiber-Glass Fiber Polystyrene}

Approximately $350 \mathrm{lbs}$ of bamboo fibers were prepared by Mini Fiber \& Resource Fiber and delivered to Techmer PM. Approximately $2000 \mathrm{lbs}$ of $15 \%$ bamboo fiber, $10 \%$ glass fiber and polystyrene pellets were prepared and used to print the final power poles. Support structures used during the printing of power poles were also used to collect tensile testing specimens. This ensures mechanical properties of the final product are consistent with the test articles. However, it seems that these support structures were not printed with optimum flow rate, and large gaps were left between beads. Therefore, only z-direction samples could be collected. We are in process of printing a more representative hexagon part and xdirection tensile properties will also be collected.

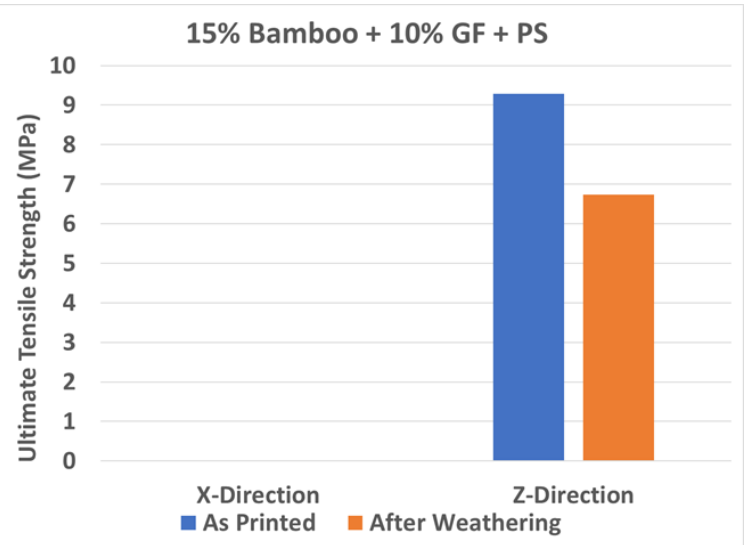

Figure 14: Bamboo+GF+PS Weathering Strength

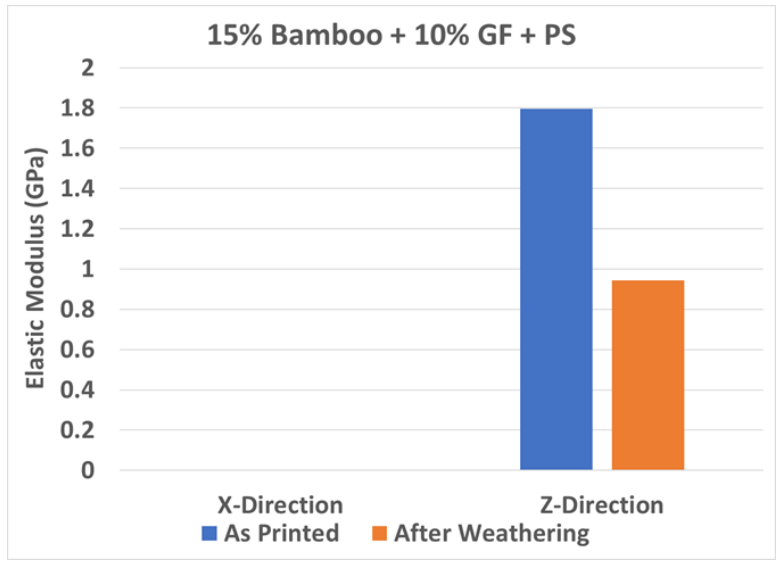

Figure 15: Bamboo+GF+PS Weathering Modulus 


\section{PRINTED POWER POLE}

Efforts likewise focused on the design and printing of a biomaterial's based power pole. Initial designs focused on light weight lattice structures (see Figure 16 and Figure 17).

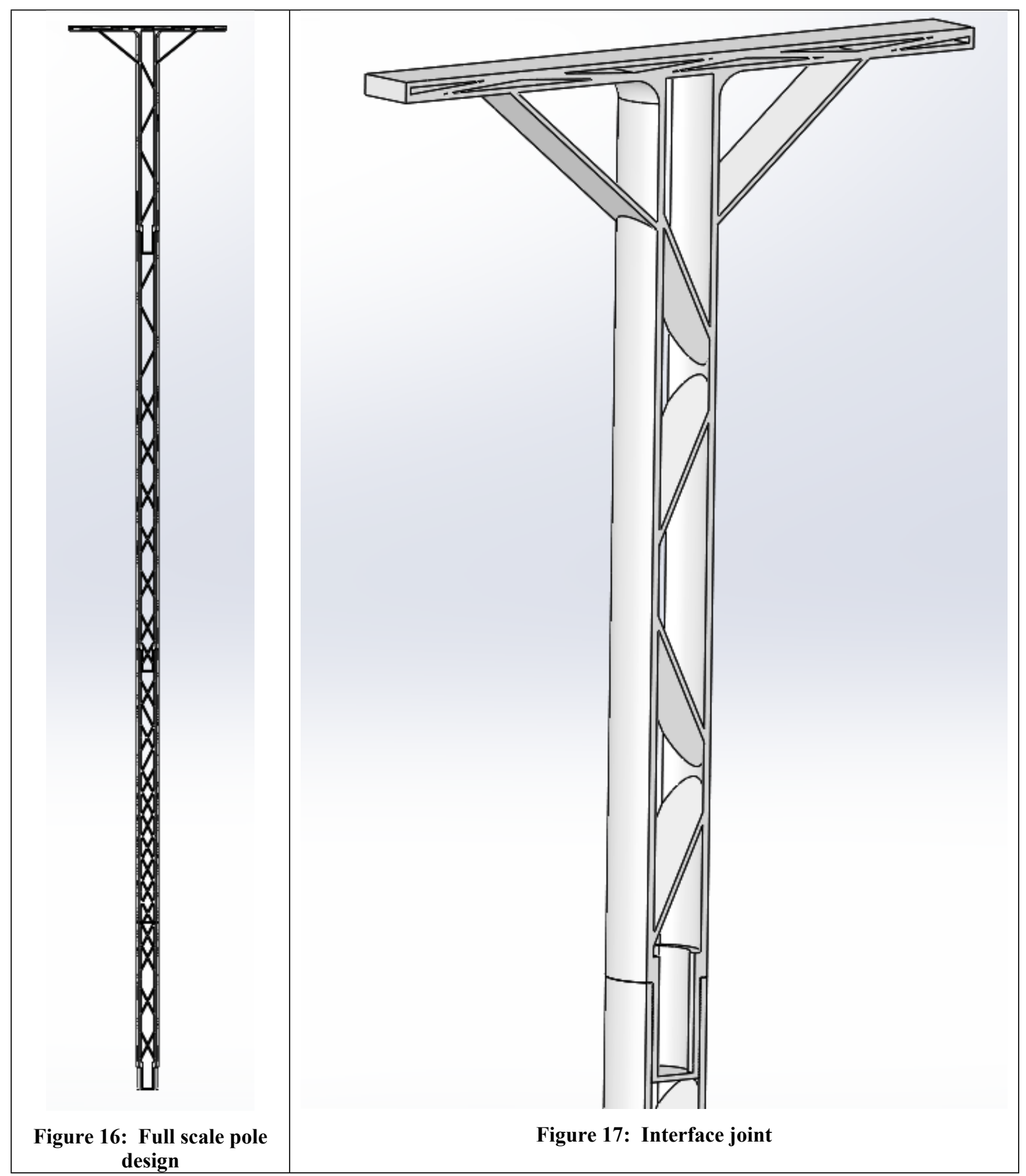


A section was printed and a 3-beam shear test was performed to validate the predicted mechanical strength (see Figure 18 and Figure 19). A good match was found between the finite element analysis and the measured load. The models suggested a failure load at $6500 \mathrm{lbs}$ whereas 3 point bending loads failed at approximately $7000 \mathrm{lb}$, well within the limits of uncertainty for printed components.

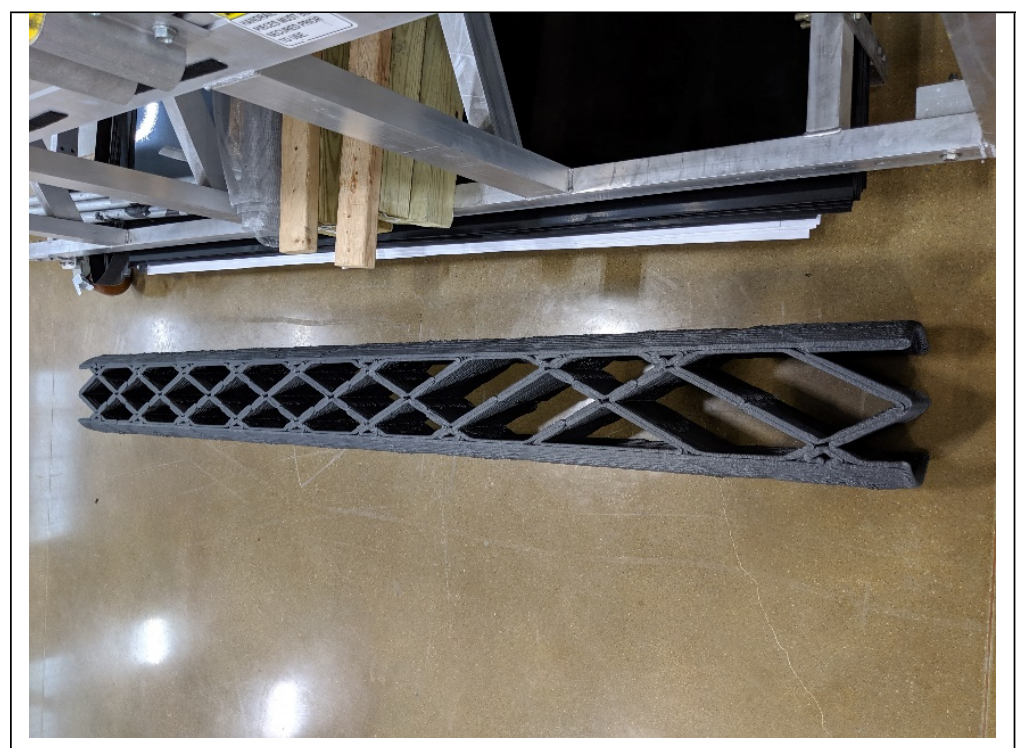

Figure 18: Prototype pole section

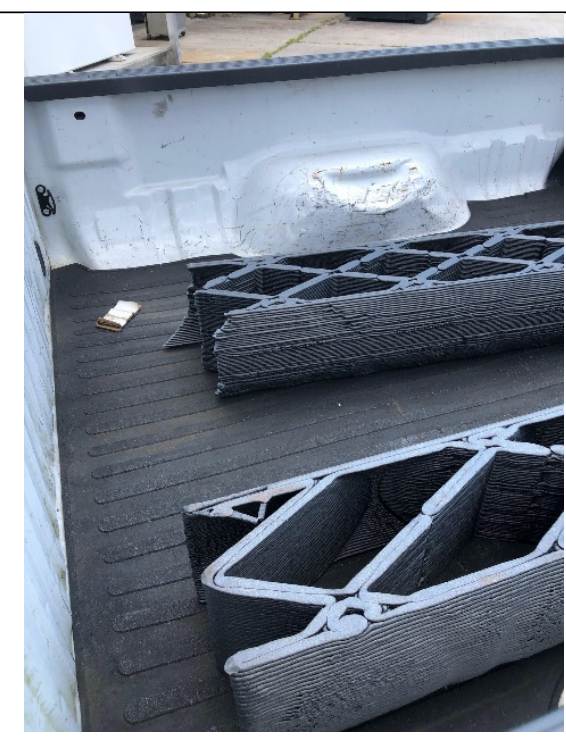

Figure 19: Load tested structure

Discussions with an industrial partner, ConEdison, suggested that an open lattice structure would not be well received. The challenge was reducing the possibility of people climbing and wildlife (birds) nesting in the structure. These factors affect the safety, maintenance and longevity of the poles. The design then shifted to a closed cylindrical structure. The pole design (see Figure 20 and Figure 21) was approximately $55 \mathrm{ft}$ in length based on a nested conical shape. The sections of the power pole can be customized to accommodate the wires that will be supported. The material selected for the prototype power pole, due to material availability, was the bamboo, glass fiber and polystyrene composite. Joints between sections were compressed and held together using turnbuckles. The modular design is easy to manufacture, transport and assemble. Utilizing this design, multiple different pole heights can be accommodated by using varying combinations of the pole sections. The system was designed to sustain a side load of $500 \mathrm{lbs}$ and had a buckling factor of safety of 18.2, side load factory of safety of 10 and gravity load factor of safety of 100 (see Figure 22 through Figure 25). The analysis confirmed the pole could stand on its own weight and could be picked up from its horizontal position. During the lift of the pole the horizontal position is where the pole will experience the greatest stress. The final assembled pole and successful lift test are shown in Figure 26 and Figure 27. 


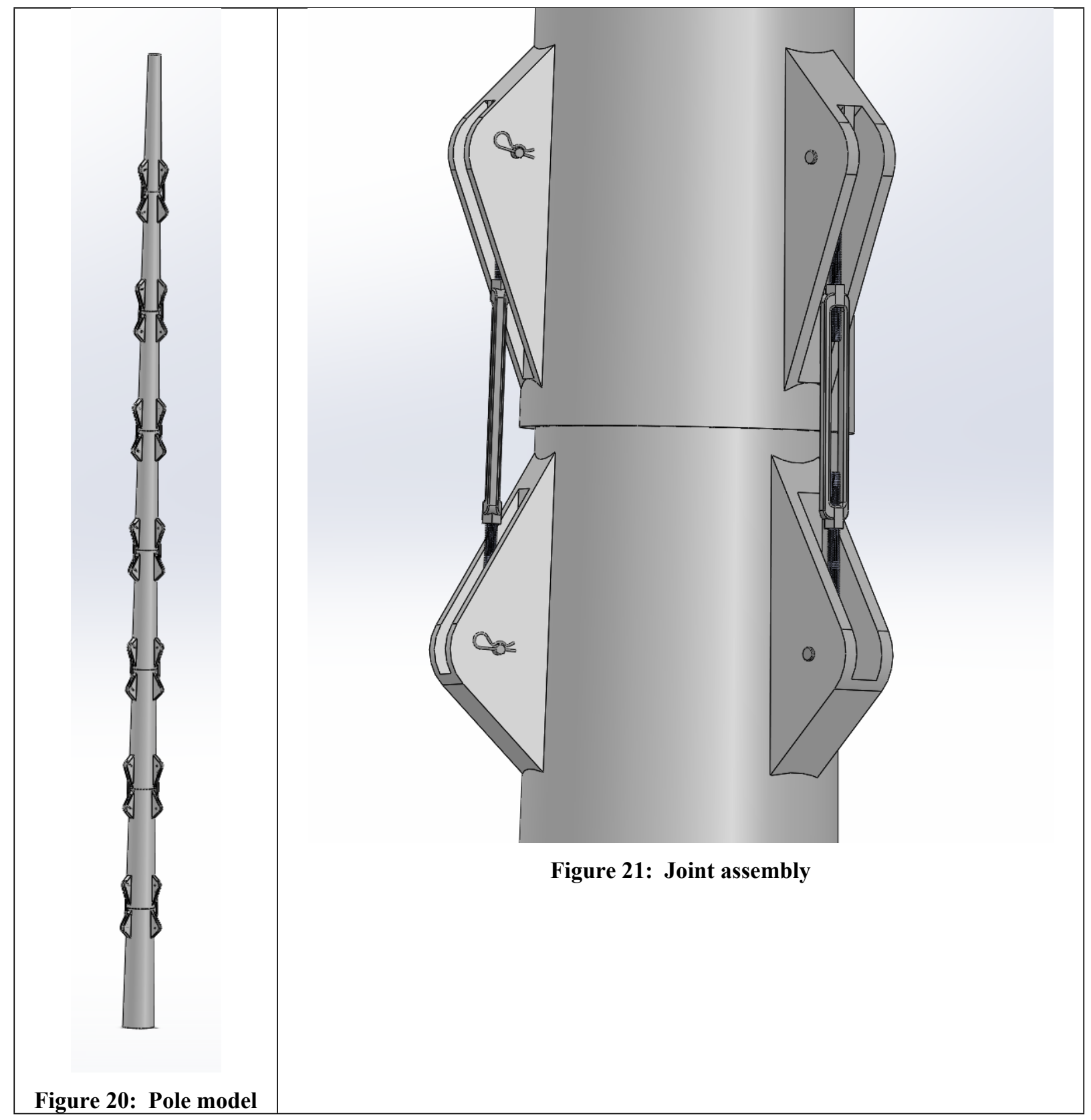



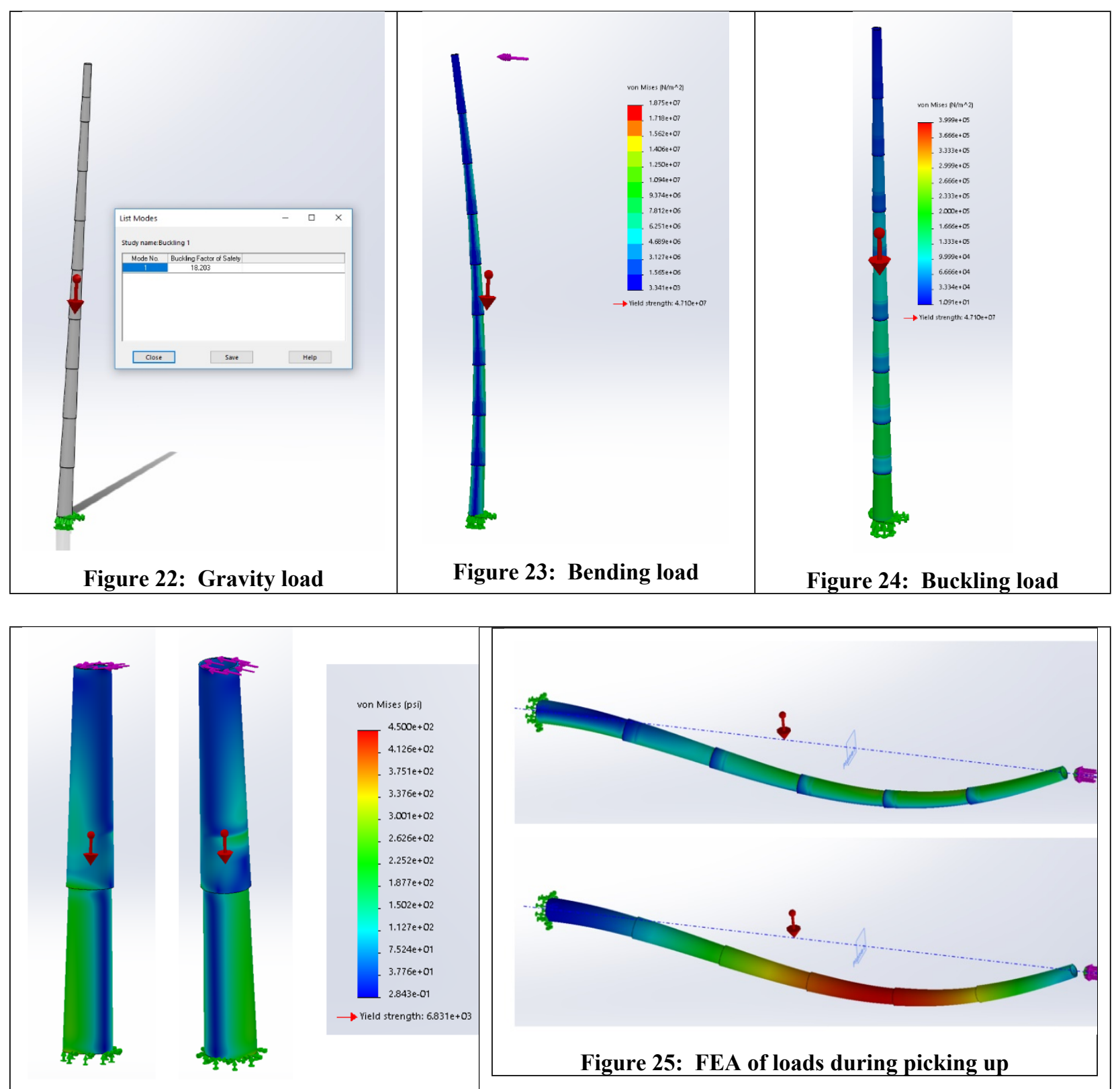


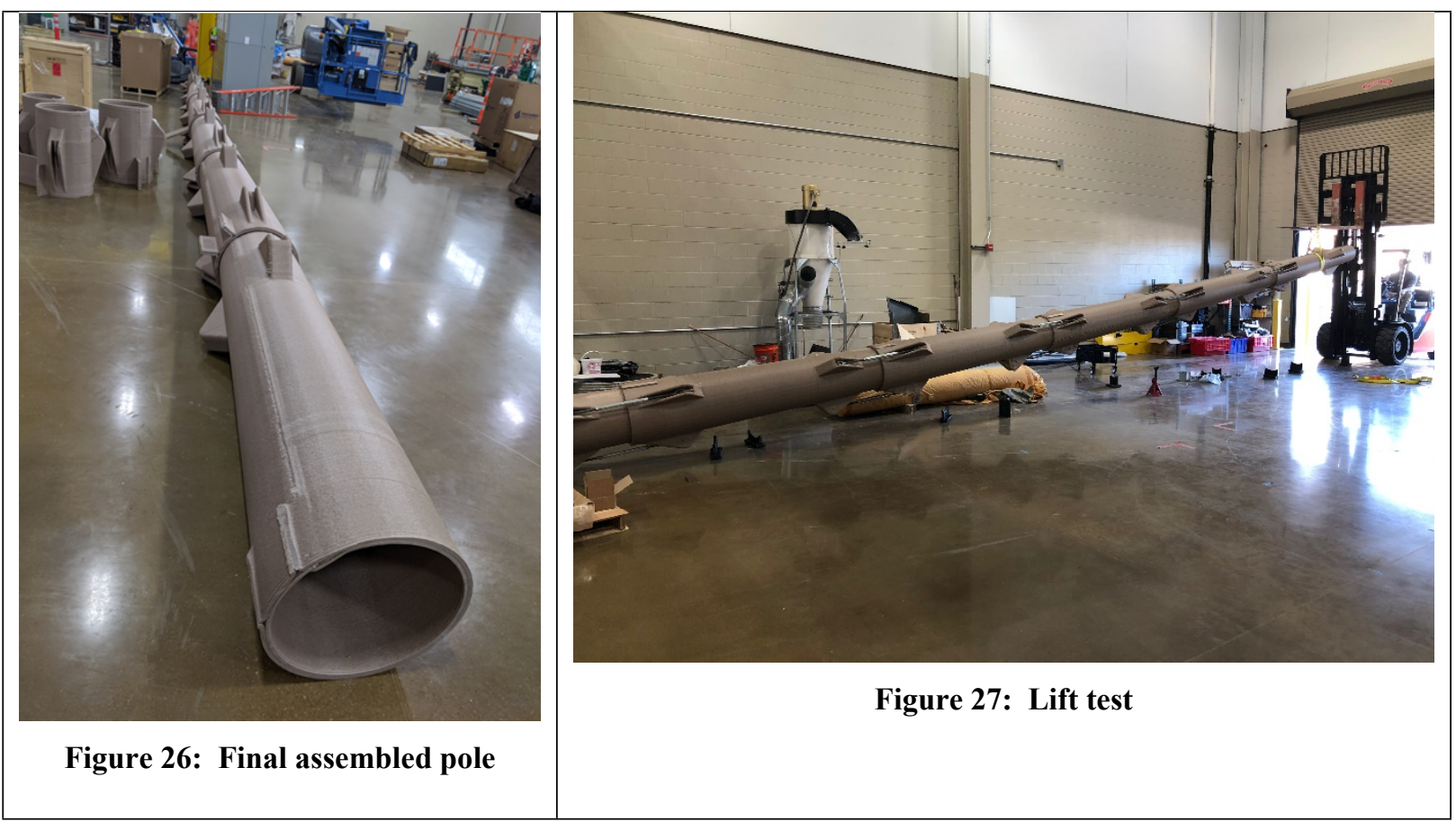

Task 2: Develop a conceptual model for portable pole production: Preliminary efforts (shown in Figure 28 and Figure 29) convey the basic concept of a power pole printer that can be assembled on the back of a truck for on-site power pole production.

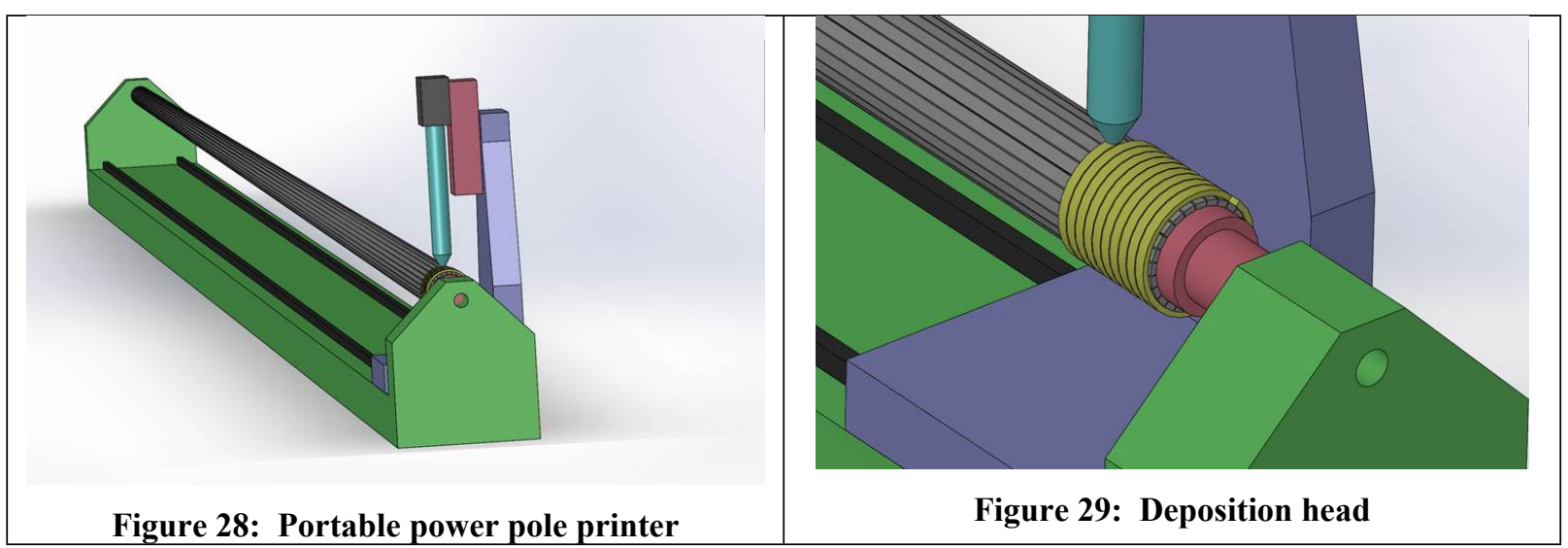




\section{IMPACTS \& CONCLUSIONS}

The goal of the program was to illustrate the ability to additively manufacture full scale power poles. In addition, there is interest in exploring printing of biomaterials for power poles. The primary impact is on-site production of power poles for disaster relief. It is imperative to get power back up immediately after a natural disaster. The ability to locally harvest biomaterials (e.g. wood debris, trees) and process on site for rapid production of power poles could have an enormous impact on recovery. Efforts in this report cover the expected mechanical properties from printed biomaterials and conceptual design and testing of printed power poles. The results are extremely promising. Future efforts need to focus on speed of production, harvesting and processing local materials and on-site manufacturing. 